\title{
SYNTHESIS, THERMAL BEHAVIOR, AND AGGREGATION IN AQUEOUS SOLUTION OF POLY(METHYL METHACRYLATE)-B-POLY(2-HYDROXYETHYL METHACRYLATE)
}

\author{
B. ACEVEDO ${ }^{1}, F . M A R T I N E Z^{2}, A . F . O L E A^{1 *}$ \\ 'Departamento de Ciencias Químicas, Facultad de Ciencias Exactas, Universidad Andrés Bello, Quillota 980, Viña del Mar, Chile. \\ ${ }^{2}$ Departamento de Ciencias de los Materiales, Facultad de Ciencias Físicas y Matemáticas, Universidad de Chile, Santiago, Chile
} (Received: July 29, 2013 - Accepted: August 28, 2013)

\begin{abstract}
Amphiphilic block copolymers of poly(methyl methacrylate) PMMA and poly(2-hidroxyethyl methacrylate) PHEMA were synthesized by a two-step atom transfer radical polymerization (ATRP). Copolymers with various degrees of polymerization and different relative block sizes were obtained. The structure of the resulting polymers have been characterized and verified by FT-IR and ${ }^{~} \mathrm{H}-\mathrm{NMR}$, molecular weight were determined by size exclusion chromatography analyses. The thermal properties of these polymers were investigated by differential scanning calorimetry DSC and thermogravimetric analysis TGA. The glass transition temperature of mono halogenated PMMA increases from $116^{\circ} \mathrm{C}$ to $123{ }^{\circ} \mathrm{C}$ with increasing molecular weight, whereas the glass transition temperature of block copolymers depends slightly on polymer structure. The derivatives of TGA curves indicate that thermal degradation occurs in one stage. The self-assembly of PMMA-b-PHEMA in aqueous solution have been investigated by fluorescence probing methods. The critical micelle concentrations are in the range $10^{-6}-10^{-7} \mathrm{M}$. The micropolarity sensed by pyrene is higher than in aggregates formed by block copolymers based on polystyrene.
\end{abstract}

Keywords: Block copolymers, glass transition temperature, thermogravimetric analysis, critical micelle concentration, fluorescence probing methods.

\section{INTRODUCTION}

Over the last decades much attention has been devoted to amphiphilic block copolymers because of their potential applications in drug delivery ${ }^{1-6}$, imaging, catalysis, etc. One of the main properties of these copolymers is the ability to self-assemble in aqueous solution forming core-shell structures ${ }^{7-9}$ The core is formed by the hydrophobic segments, whereas the hydrophilic segments form the shell which provides solubility in water and stability to the aggregates. A number of hydrophilic polymers have been used but poly(ethylene glycol) PEO is the most common due to its unique properties, and many studies on PEO-based copolymers have been reported ${ }^{10-12}$. Recently, poly(2-hydroxyethyl methacrylate) (PHEMA)) has attracted great interest because this polymer exhibits excellent biocompatibility ${ }^{13}$ and good blood compatibility ${ }^{14}$. PHEMA is a commercially available polymer and find a number of interesting applications, such as hydrogel ${ }^{15,16}$, soft contact lenses applications ${ }^{17}$, tissue engineering ${ }^{18}$. These features have prompted much interest on block copolymers containing PHEMA ${ }^{19-21}$. Since the discovery of atom transfer radical polymerization (ATRP) ${ }^{22,23}$ a number of polymers has been synthesized by using this technique ${ }^{24}$. In particular, homopolymers of HEMA and HEMA-based block copolymers of controlled molecular weight and low polydispersity have been synthesized by ATRP ${ }^{20,25-31}$. Due to poor solubility of PHEMA in non polar solvents ATRP has been carried out in methano ${ }^{28}$ and a combination of methyl ethyl ketone and 1-propanol $(70: 30 \mathrm{v} / \mathrm{v})^{25}$, but high molecular weights could not be obtained. To overcome these difficulties an alternative approach that involves three steps has been used: protection of the hydroxyl group of HEMA, ATRP polymerization of the less polar monomer, and subsequent removal of the protecting groups $\mathrm{s}^{31,32}$.

The aim of this work is to investigate the thermal properties in bulk, and self-assembling in aqueous solution, of amphiphilic block copolymers formed by PMMA and PHEMA as a function of the polymer structure.

\section{EXPERIMENTAL PART}

2.1 Materials. Tetrahydrofurane (THF, Aldrich), dichloromethane (Aldrich), imidazole (Merck), p-Toluenesulfonyl chloride (TosCl, Merck), tert-butyldimethylchlorosilane (TBDMS, Merck), 2,2'-bipyridine (bpy, Aldrich) and tetrabutylammonium fluoride $\left(\left(\mathrm{C}_{4} \mathrm{H}_{0}\right)_{4} \mathrm{NF}, 1.0 \mathrm{M}\right.$ solution in THF Aldrich) were used without further purification. $\mathrm{N}, \mathrm{N}, \mathrm{N}^{\prime}, \mathrm{N}^{\prime \prime}, \mathrm{N}^{\prime \prime}-$ pentamethyldiethylenetriamine (PMDETA, 98\% Aldrich) was purified by passing through a neutral alumina column before use. Methyl methacrylate (MMA, Fluka AG) was washed three times with $5 \%$ aqueous $\mathrm{NaOH}$ solution and once with distilled water to remove any inhibitor. The solution was dried over $\mathrm{MgSO}_{4}$, filtered, and then distilled under reduced pressure from $\mathrm{CaH}_{2}$.

2.2 Purification of catalyst. Copper (I) chloride (Merck) was purified by reducing $\mathrm{Cu}(\mathrm{II})$ with sodium sulfite according to the following procedure: An aqueous solution of sodium sulfite is added slowly, with constant stirring, to a $\mathrm{CuCl}$ solution. Solid $\mathrm{CuCl}$ is obtained by adding an excess of sulfurous acid solution. The precipitate is washed with glacial acetic acid and ethanol and dried under vacuum for $8 \mathrm{~h}$. 2-hydroxyethyl methacrylate (HEMA, Aldrich $85 \%$ ) was distilled under reduced pressure using a Glass Oven B-585 Kugelrohr (Buchi) and then passed through a neutral alumina column.

2.3 Synthesis of HEMA-TBDMS. The protected monomer HEMA-TBDMS was synthesized following a reported method for anionic polymerization ${ }^{33}$. HEMA $(5.37 \mathrm{~g}, 0.041 \mathrm{~mol})$ in THF $(50 \mathrm{~mL})$ and imidazole $(5.6 \mathrm{~g}, 0.082 \mathrm{~mol})$ in THF $(50 \mathrm{~mL})$ were mixed into a three-neck-flask equipped with thermometer, condenser, and nitrogen bubbling. After cooling to $0^{\circ} \mathrm{C}$ TBDMS $(6.20 \mathrm{~g}, 0.041$ $\mathrm{mol})$ in $\mathrm{CH}_{2} \mathrm{Cl}_{2}(30 \mathrm{~mL})$ was added slowly under stirring. After $18 \mathrm{~h}$ the white salt precipitate was filtered, the residue was redissolved in THF and passed through a neutral alumina column. The solvent was eliminated under reduced pressure and the product was dried at $50 \mathrm{C}$ for $24 \mathrm{~h}$. IR: $\boldsymbol{V}\left(\mathrm{cm}^{-1}\right) 2957,2927$, $2854\left(\mathrm{~m},(\mathrm{CH})_{3}\right), 1718(\mathrm{~s}, \mathrm{C}=\mathrm{O}), 1170,1110\left(\mathrm{C}-\mathrm{O}-\mathrm{CH}_{2}\right), 1637(\mathrm{~s}, \mathrm{C}=\mathrm{C}), 941$ (s, $\left.\mathrm{O}-\mathrm{Si}-\mathrm{CH}_{3}\right), 1250$ and $836\left(\mathrm{~s}, \mathrm{Si}\left(\mathrm{CH}_{3}\right)_{3}\right)$

2.4 Synthesis of macroinitiator. The macroinitiators, PMMA-Cl, were obtained by ATRP using $\mathrm{CuCl} / \mathrm{PMDETA}$ as catalyst. In a typical polymerization experiment, PMDETA ( $36.4 \mathrm{mg}, 0.21 \mathrm{mmol}), \mathrm{CuCl},(10.4 \mathrm{mg}$, $0.105 \mathrm{mmol}$ ) and MMA (4.68 g, $46.7 \mathrm{mmol}$ ) are mixed in a Schlenk flask. Oxygen is removed by three cycles of freeze-vacuum-thaw $\left(1.33 \times 10^{-4} \mathrm{kPa}\right)$. Then, p-Tos Cl ( $40 \mathrm{mg}, 0.209 \mathrm{mmol})$ in $5 \mathrm{~mL}$ of THF is added under nitrogen atmosphere, and the mixture was heated at $90^{\circ} \mathrm{C}$ for 8 hours with magnetic stirring. After this time, the solution was exposed to air and diluted with THF. The solution was passed through a neutral alumina column to remove the copper catalyst. The resulting solution was precipitated twice by pouring it on methanol, and then dried at $30^{\circ} \mathrm{C}$ under vacuum to a constant weight. Yield: 96\%. ${ }^{1} \mathrm{H}$ NMR (acetone- $\mathrm{d}_{6}$ ), $400 \mathrm{MHz}: \delta 8.0-7.5(\mathrm{~d}, \mathrm{ArH}), 3.5-3.8\left(\mathrm{~s}, \mathrm{OCH}_{3}\right.$ ), $2.5\left(\mathrm{~s}, \mathrm{CH}_{3}-\mathrm{Ar}\right), 2.0-1.7\left(\mathrm{~m}, \mathrm{CH}_{2}\right), 1.02-0.83\left(\mathrm{~s}, \mathrm{CH}_{3}\right)$

2.5 Synthesis of PMMA-b-PHEMA. This block copolymer was synthesized in two steps: ATRP polymerization of protected HEMA using PMMA-Cl as macroinitiator, followed by the deprotection reaction. In a typical experiment, the macroinitiator PMMA-Cl $\left(473 \mathrm{mg}, 0.0172 \mathrm{mmol} M_{\mathrm{n}}=2.75 \times 10^{4}\right)$ was dissolved in $3 \mathrm{~mL}$ of a 30:70 mixture of propanol and butanone. The solution is degassed by $\mathrm{N}_{2}$ bubbling during $15 \mathrm{~min}$. In a Schlenk flask, with magnetic stirring, BPy, (0.011 g, $0.0704 \mathrm{mmol}), \mathrm{CuCl}(0.035 \mathrm{~g}, 0.354 \mathrm{mmol})$, and HEMATBDMS $(1.07 \mathrm{~g}, 0.0412 \mathrm{mmol})$ were mixed. The mixture was degassed by three freeze-vacuum-thaw cycles and a strong red color is observed. After the Schlenk flask was heated at $65^{\circ} \mathrm{C}$ for $5 \mathrm{~min}$, the macroinitiator solution was added. The mixture is reacted by $12 \mathrm{~h}$ at $65^{\circ} \mathrm{C}$. This mixture was dissolved in $5 \mathrm{~mL}$ of THF and the corresponding solution was purified by passing it through a silica column to completely remove the catalyst.

To hydrolyze the TBDMS groups in the resulting polymers a solution of $\left(\mathrm{C}_{4} \mathrm{H}_{9}\right)_{4} \mathrm{NF}$ in THF $(0.028 \mathrm{~mL}, 0.028 \mathrm{mmol})$ was added to (PHEMA-TBDMS)- 
b-PMMA (0.1 g, $0.002 \mathrm{mmol})$ dissolved in $5 \mathrm{~mL}$ of THF. The solution was stirred at $25^{\circ} \mathrm{C}$ for $24 \mathrm{~h}$. The deprotected polymer was precipitated by pouring the solution into methanol/water $(90: 10)$. The yield was $95 \%$. IR: $\boldsymbol{V}$ $\left(\mathrm{cm}^{-1}\right): 3600\left(\mathrm{CH}_{2}-\mathrm{OH}\right), 1718(\mathrm{~s}, \mathrm{C}=\mathrm{O}), 1170-1110\left(\mathrm{C}-\mathrm{O}-\mathrm{CH}_{2}\right) . \quad{ }^{1} \mathrm{H}-\mathrm{NMR}$ (acetone- $\mathrm{d}_{6}$ ), 400 MHz: $\delta$ 8.0, $7.5(\mathrm{~d}, \mathrm{ArH}), 3.5-3.8\left(\mathrm{~s}, \mathrm{OCH}_{3}\right), 3.8-4.0(\mathrm{~d}$, OCO- $\left.\mathrm{CH}_{2}-\mathrm{CH}_{2}\right), 2.5\left(\mathrm{~s}, \mathrm{CH}_{3}-\mathrm{Ar}\right), 2.0-1.7\left(\mathrm{~m}, \mathrm{CH}_{2}\right), 1.5-1.8\left(\mathrm{~s}, \mathrm{CH}_{3}\right)$.

2.6 Copolymer Characterization. The number average $\left(M_{\mathrm{n}}\right)$ and weight average $\left(M_{\mathrm{w}}\right)$ molecular weights were determined by size exclusion chromatography (SEC) using a LC-20AD Prominence, Shimadzu with RI detector, and two GPC columns (MZ-Gel SD plus 10000 and $100000 \mathrm{~A}$ ). The data was stored and processed with Class VP software. The samples were dissolved in THF $(20 \mathrm{mg} / \mathrm{mL})$ and eluted with THF at a flow rate of $0.400 \mathrm{~mL} /$ min. The calibration curve was performed using polystyrene standards.

FT-IR spectra were recorded on a Bruker Vector 22 (Bruker Optics GmbH, Inc., Ettlingen, Germany) spectrometer. ${ }^{1} \mathrm{H}-\mathrm{NMR}$ spectra were recorded in solution at room temperature with a Bruker Avance 400 Digital (Bruker, Karlsruhe, Germany) spectrometer using deuterated acetone as the solvent.

2.7 Thermal behavior. The thermal stability and glass transition temperatures of the polymers were determined by Thermal Gravimetric Analysis (TGA) and Differential Scanning Calorimetry (DSC), respectively.

Thermal stability studies were performed using a TGA Q50, TA Instruments. The instrument was calibrated both for temperature and weight by usual methods. The weight loss percentage was determined over the temperature range 20 to $600{ }^{\circ} \mathrm{C}$ at a scan rate of $10{ }^{\circ} \mathrm{C} / \mathrm{min}$. The average sample weight was $6 \mathrm{mg}$ and the dry nitrogen flow rate $40 \mathrm{~mL} / \mathrm{min}$. The glass transition temperatures were determined by using a Mettler Toledo Star System 822e. DSC measurements were carried out to determine the copolymer's glass transition temperature $(\mathrm{Tg})$. The $\mathrm{Tg}$ was measured at a heating rate of $10^{\circ} \mathrm{C} /$ min under dry nitrogen $(25 \mathrm{~mL} / \mathrm{min})$ over a temperature range from 30 to $200{ }^{\circ} \mathrm{C}$. To eliminate the effect of thermal history on the phase transitions, all samples were heated to $150{ }^{\circ} \mathrm{C}$, held at that temperature for $5 \mathrm{~min}$ and then cooled to $30^{\circ} \mathrm{C}$.

\section{RESULTS AND DISCUSSION}

3.1 Synthesis of polymers. The amphiphilic block copolymer PMMA-bPHEMA was synthesized by two successive ATRP polymerizations. Firstly, well-defined chloride terminated PMMA chains were obtained by ATRP using $\mathrm{p}$-TosCl/CuCl/PMDETA system. A series of PMMA-Cl with different molecular weights was synthesized by varying the initiator concentration. The characterization of PMMA-Cl was carried out by FTIR, ${ }^{1} \mathrm{H}-\mathrm{NMR}$, and SEC. The SEC results presented in Table 1 show that the molecular weight of the formed polymer decreases linearly with increasing $\mathrm{p}-\mathrm{Tos} \mathrm{Cl}$ concentration. The data of Table 1 show that polymers with a relatively low polydispersity PD, of different degrees of polymerization DP, can be obtained. These results indicate that $\mathrm{p}$-TosCl/PMDETA is an effective initiator system, and confirm that ATRP systems using PMDETA as metal complex ligand afford polymers in high yields and with narrow molecular weight distribution ${ }^{31}$.

Table 1. Results of SEC measurements for ATRP polymerization of MMA in THF using p-TosCl/PMDETA as initiator system.

\begin{tabular}{|c|c|c|c|c|c|c|}
\hline PMMA & $\begin{array}{c}\text { p-TosCl } \\
(\mathbf{m m o l})\end{array}$ & Yield & Mn & Mw & PD & DP \\
\hline H1 & 0.525 & 85.2 & 6700 & 7360 & 1.09 & 67 \\
\hline H2 & 0.399 & 92.1 & 20760 & 23380 & 1.13 & 207 \\
\hline H3 & 0.266 & 94.4 & 27540 & 36850 & 1.33 & 275 \\
\hline H4 & 0.199 & 77.4 & 33020 & 47650 & 1.44 & 330 \\
\hline H5 & 0.133 & 92.5 & 56250 & 58830 & 1.05 & 562 \\
\hline
\end{tabular}

In the second step, hydrophilic blocks of PHEMA were added to PMMA polymer chains by using PMMA-Cl as part of the initiating system in an ATRP polymerization. Thus, the amphiphilic character of the block copolymer can be modulated by using PMMA-Cl of different molecular weight as macroinitiator, and/or by varying the degree of polymerization of HEMA in the second block (see Table 2). The initial attempt to polymerize HEMA with $\mathbf{H 3}$ gave a polymer with a very low number of HEMA units, probably due to poor solubility of PHEMA in organic solvents. For this reason the monomer was polymerized in its protected form, and TBDMS was used as protective group because it exhibits higher stability compared to trimethylsilane. The ATRP conditions were similar to those used to polymerize PMMA, and the degree of polymerization for the PHEMA block was varied by changing the feeding ratio of protected HEMA. The characterization of PMMA-b-PHEMA was carried out by FTIR, ${ }^{1} \mathrm{H}-\mathrm{NMR}$, and SEC. In Figure 1 are compared the SEC chromatograms obtained for the macroinitiator $\mathbf{H 2}$ and the block copolymer C2.

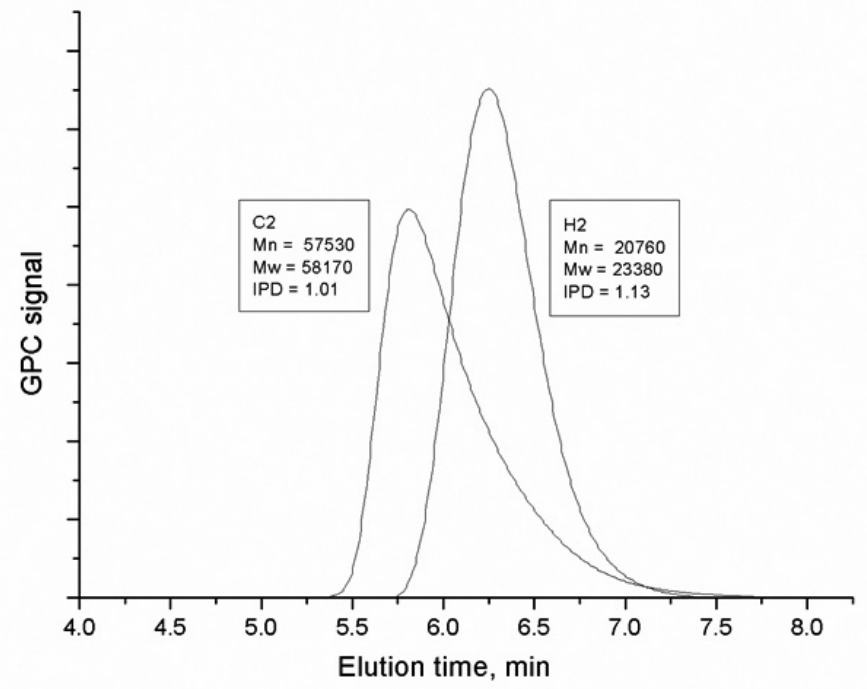

Figure 1. SEC chromatograms of PMMA-Cl (H2) and block copolymer PMMA-b-PHEMA protected with TBDMS (C2). Both polymers were dissolved in THF.

The molar mass distributions of both polymers are monomodal indicating that no homopolymers of HEMA were formed. The molecular weight and polydispersities of block copolymers are summarized in Table 2 .

Table 2. Molecular weights, polydispersities and composition of block copolymers.

\begin{tabular}{|c|c|c|c|c|c|}
\hline Sample & $\begin{array}{c}\text { PMMA- } \\
\text { Cl }\end{array}$ & Mn & Mw & PD & Composition \\
\hline C1 & H1 & 44230 & 45260 & 1.02 & $\begin{array}{c}\text { PMMA }_{67} \text {-b- } \\
\text { PHEMA }_{154}\end{array}$ \\
\hline C2 & H2 & 58170 & 57530 & 1.01 & $\begin{array}{c}\text { PMMA }_{207} \text {-b- } \\
\text { PHEMA }_{153}\end{array}$ \\
\hline C3 & H2 & 53690 & 53210 & 1.01 & $\begin{array}{c}\text { PMMA }_{207} \text {-b- } \\
\text { PHEMA }_{135}\end{array}$ \\
\hline C4 & H3 & 28880 & 36850 & 1.27 & $\begin{array}{c}\text { PMMA }_{275} \text {-b- } \\
\text { PHEMA }_{10}\end{array}$ \\
\hline C5 & H3 & 49130 & 52820 & 1.07 & $\begin{array}{c}\text { PMMA }_{275} \text {-b- } \\
\text { PHEMA }_{88}\end{array}$ \\
\hline
\end{tabular}

The results indicate that ATRP polymerization allows chain extension of PMMA and the growth in molecular weight can be attributed exclusively to PHEMA block formation. The different degrees of polymerization of this block and the low values of polydispersities indicate that a good control of block copolymerization is achieved by using PMMA- $\mathrm{Cl}$ as macroinitiator.

Finally, the block copolymers were reacted with $\left(\mathrm{C}_{4} \mathrm{H}_{0}\right)_{4} \mathrm{NF}$ in order to remove the TBDMS groups that were used to protect the hydroxyl groups. The complete removal of the TBDMS and formation of hydroxyl groups was confirmed by FTIR and ${ }^{1} \mathrm{H}-\mathrm{NMR}$.

Recently, a different approach to synthesize amphiphilic block copolymers containing a higher ratio of HEMA has been reported ${ }^{29}$. In this scheme PHEMA-Cl is used as macroinitiator, and block copolymers of PHEMA with PS and poly(phenylmaleimide) were obtained without group protection ${ }^{29}$.

3.2 Thermal Analysis. The thermal behavior of PMMA-Cl and PMMA-bPHEMA was investigated by TGA and DSC. The TGA curves obtained for the different PMMA macroinitiators and block copolymers are shown in Figures 2 and 3 , respectively. 


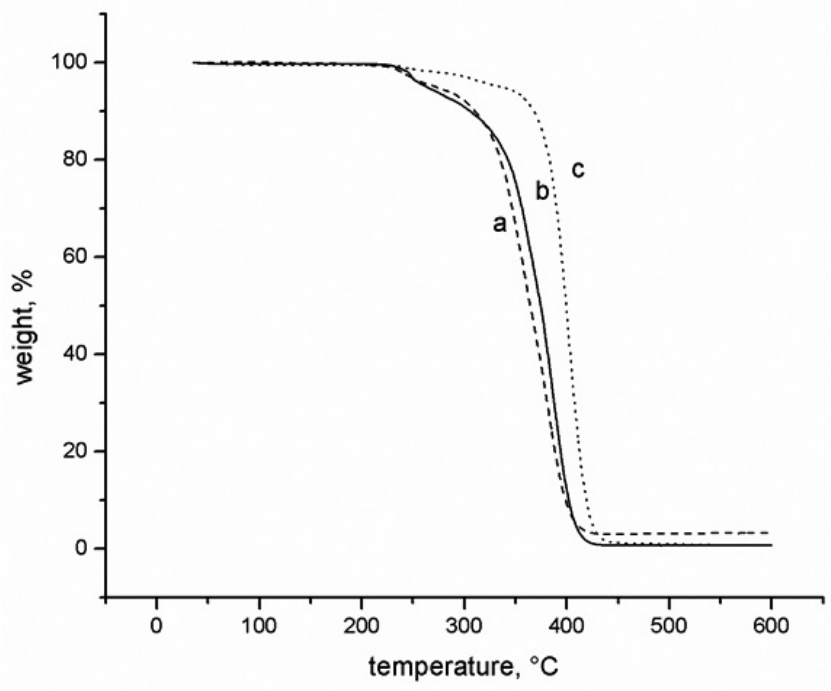

Figure 2. TGA thermograms of PMMA-Cl of different degrees of polymerization: (a) H1; (b) $\mathrm{H} 2$; (c) $\mathrm{H} 3$.

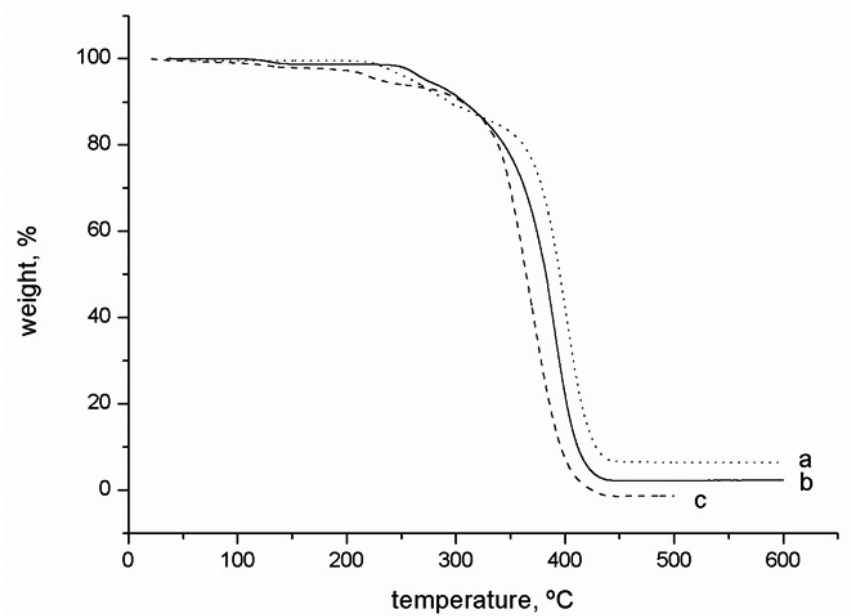

Figure 3. TGA thermograms of PMMA-b-PHEMA of different composition: (a) $\mathrm{C} 1$; (b) $\mathrm{C} 2$; (c) $\mathrm{C} 4$.

From the TGA curves the temperatures of $5 \%$ and $50 \%$ mass loss, $T_{50 \%}$ $T_{500}$, were obtained. In addition, from the derivative of weight loss curves the temperatures of maximum loss were determined. The results are summarized in Table 3. The derivatives of TGA curves show a single peak, which indicate one reaction stage for thermal degradation. For all studied systems the main part of mass loss occurs above $350{ }^{\circ} \mathrm{C}$, suggesting that degradation is due to random chain scission ${ }^{34}$. On the other hand, the TGA curves obtained for some PMMAb-PHEMA block copolymers exhibit initial degradation at lower temperatures, which can be attributed to water linked to the hygroscopic PHEMA block. In HEMA polymers and copolymers bound water might reach up to $10 \%$ of the mass loss ${ }^{29,35}$.

The glass transition temperatures of PMMA-Cl and block copolymers were determined by DSC. For all block copolymers and PMMA homopolymers, a single glass transition temperature is detected, and their values depend slightly on copolymer composition and on molecular weight of PMMA (see Figures $3-4)$. This suggests that the copolymers have a random copolymer structure for all compositions. However, for all block copolymers the $T$ values obtained are lower than those measured for the respective PMMA-Cl, and higher than the $T$ of pure PHEMA $\left(87^{\circ} \mathrm{C}\right)^{35}$. These results indicate that in the glassy state the polymer chains are statistically distributed, and no microphase structures are formed by the amphiphilic block copolymer.
Table 3. Glass transition temperature $T_{g}$, temperatures of $5 \%$ and $50 \%$ mass loss $T_{5 \%}, T_{50 \%}$ and maximum temperature of mass loss $T_{m}$

\begin{tabular}{|c|c|c|c|c|c|}
\hline Polymer & $\begin{array}{c}T_{g} \\
\left({ }^{\circ} \mathrm{C}\right)\end{array}$ & $\begin{array}{c}T_{5 \%} \\
\left({ }^{\circ} \mathrm{C}\right)\end{array}$ & $\begin{array}{l}T_{50 \%} \\
\left({ }^{\circ} \mathrm{C}\right)\end{array}$ & $\begin{array}{l}T_{\max } \\
\left({ }^{\circ} \mathrm{C}\right)\end{array}$ & $\begin{array}{c}\% \text { mass } \\
\text { loss }\end{array}$ \\
\hline PMMA $_{67}$ & 116.3 & 335 & 399 & 399 & 48.7 \\
\hline $\mathrm{PMMA}_{207}$ & 121.7 & 263 & 374 & 387 & 70.0 \\
\hline $\mathrm{PMMA}_{275}$ & 122.9 & 272 & 364 & 384 & 74.8 \\
\hline PMMA $_{67}$-b-PHEMA ${ }_{154}$ & 108.8 & 260 & 395 & 402 & 61.4 \\
\hline PMMA $_{207}$-b-PHEMA & - & 136 & 372 & 388 & 74.7 \\
\hline PMMA $_{207}$-b-PHEMA ${ }_{153}$ & 116.0 & 273 & 383 & 391 & 63.7 \\
\hline PMMA $_{275}$-b-PHEMA 88 & 113.9 & 176 & 371 & 376 & 56.4 \\
\hline
\end{tabular}

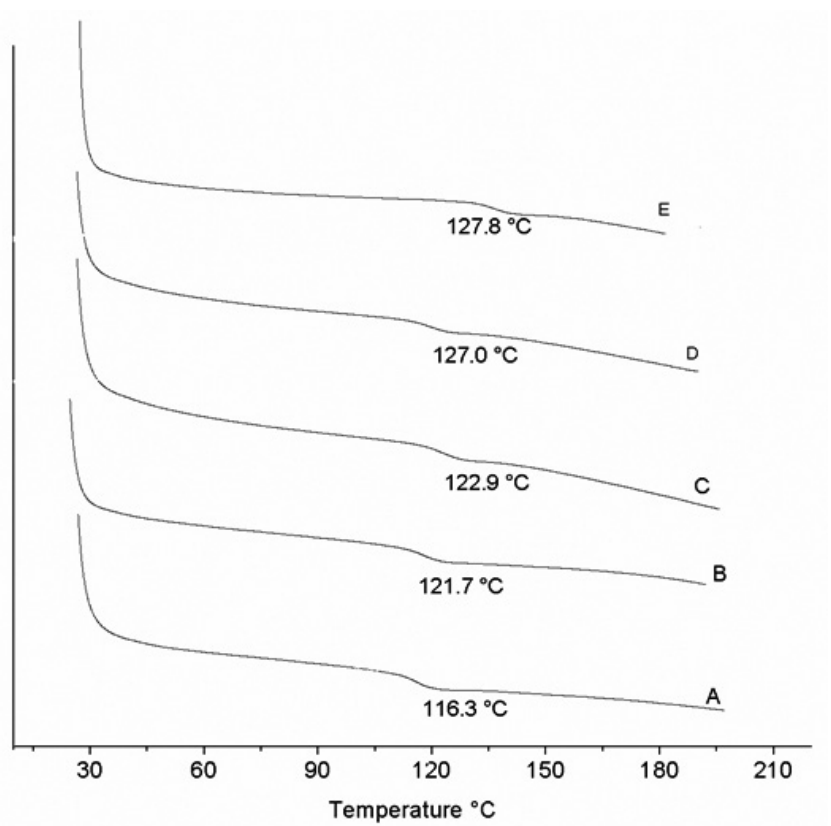

Figure 4. DSC thermograms of macroinitiators PMMA-Cl: (A) H1; (B) $\mathrm{H} 2$; (C) H3; (D) H4; (E) H5.

3.3 Self-assembly of diblock copolymers in aqueous solution. The selfassembly of PMMA-b-PHEMA in aqueous solution was monitored by fluorescence probing methods and using pyrene as fluorescent probe. Pyrene has been widely used in the study of microheterogeneous systems because its fluorescence and excitation spectra changes with the polarity of the environment where it is located ${ }^{36}$. Based on the changes of emission and excitation spectra of pyrene with polymer concentration several methods to determine the critical micelle concentration CMC of block copolymers have been proposed ${ }^{37,38}$. The most accepted method has been proposed by Wilhelm et al. and uses the effect of polymer concentration on the excitation spectra of pyrene ${ }^{38}$. Briefly, the excitation spectra exhibit a red shift of the band $(0,0)$ from 333 to $338 \mathrm{~nm}$ upon the increment of block copolymer concentration (see figure 6). The extreme values of the ratio $\mathrm{I}_{338} / \mathrm{I}_{333}=\mathrm{F}$ allow the measurement of the ratio of pyrene solubilized into the micelle over the concentration of pyrene in the aqueous phase according to

$$
\frac{[P y]_{M}}{[P y]_{W}}=\frac{F-F_{\min }}{F_{\max }-F}=K C
$$




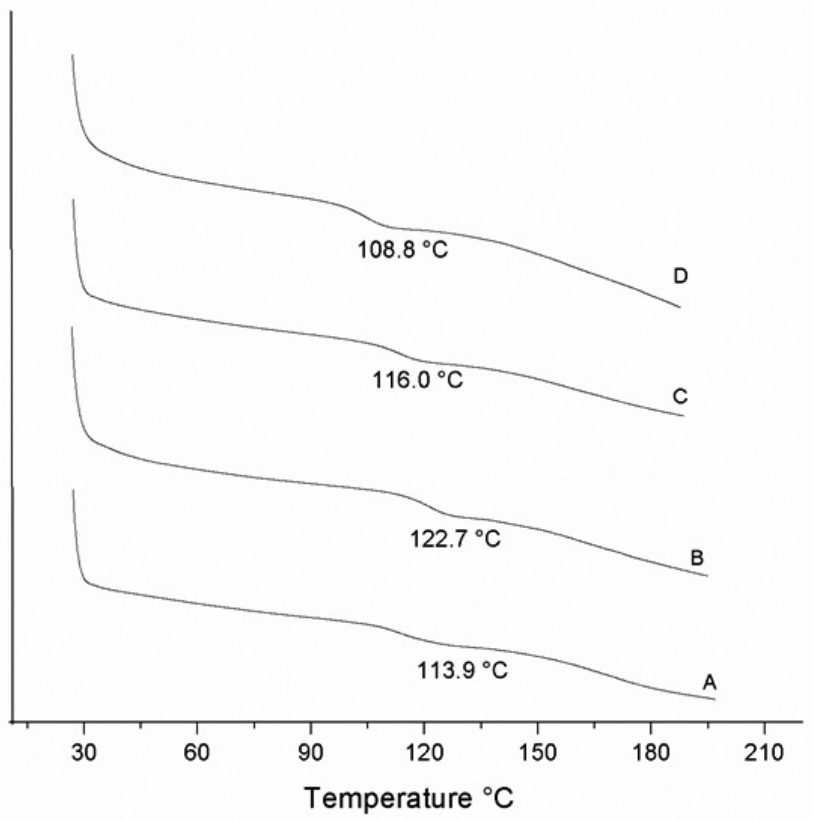

Figure 5. DSC thermograms of block copolymers: (A) C5; (B) C4; (C) C2; (D) C1.

where $\mathrm{K}$ is a constant that includes the distribution constant of pyrene between the aqueous and micellar phases, and $\mathrm{C}$ represents the polymer concentration. In a plot of this ratio against polymer concentration the data can be fitted to two intersecting straight lines, and the CMC is given by the extrapolated intercept with the $\mathrm{C}$ axis. In figure 7 are shown the results obtained by plotting Wilhelm's equation for $\mathrm{C} 4$ block copolymer. The CMC values obtained with this method are in the range $10^{-6}-10^{-7} \mathrm{M}$ (see table 4), and they are similar to those reported for block copolymers based on polystyrene PS $^{5,6,37,38}$.

The data indicate that the CMC depends on the size of the hydrophilic block, i.e. for copolymers with the same PMMA block, CMC increases with increasing number of HEMA units. In other words, the aggregation starts at lower concentrations in those copolymers with the smallest hydrophilic block. This result suggests that, in addition to the hydrophobic effect of the PMMA chains, the interaction of HEMA groups with water makes an important contribution to the driving force for the aggregation process.

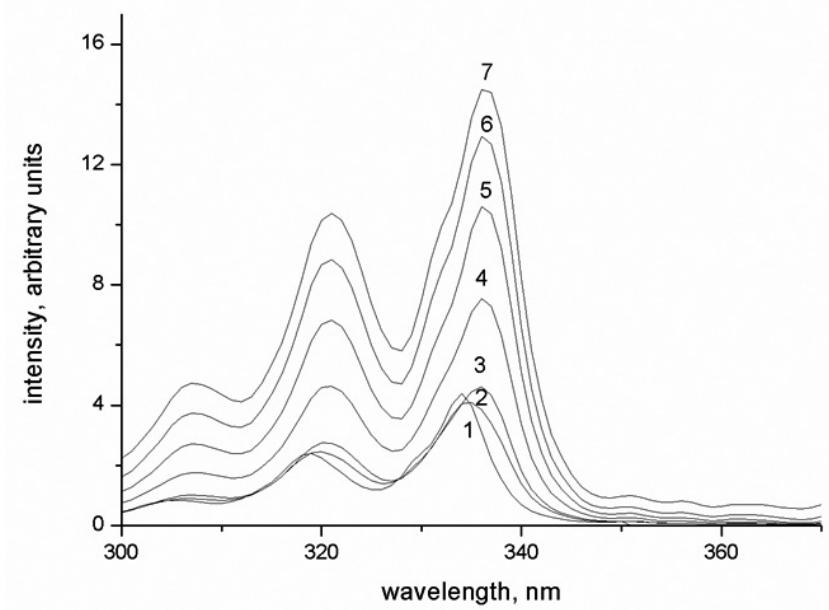

Figure 6. Excitation spectra of pyrene at different concentrations of $\mathrm{C} 4$ : (1) $0 \mu \mathrm{M}$; (2) $29 \mu \mathrm{M}$; (3) $57 \mu \mathrm{M}$; (4) $140 \mu \mathrm{M}$; (5) $350 \mu \mathrm{M}$; (6) $890 \mu \mathrm{M}$; (7) $2200 \mu \mathrm{M}$

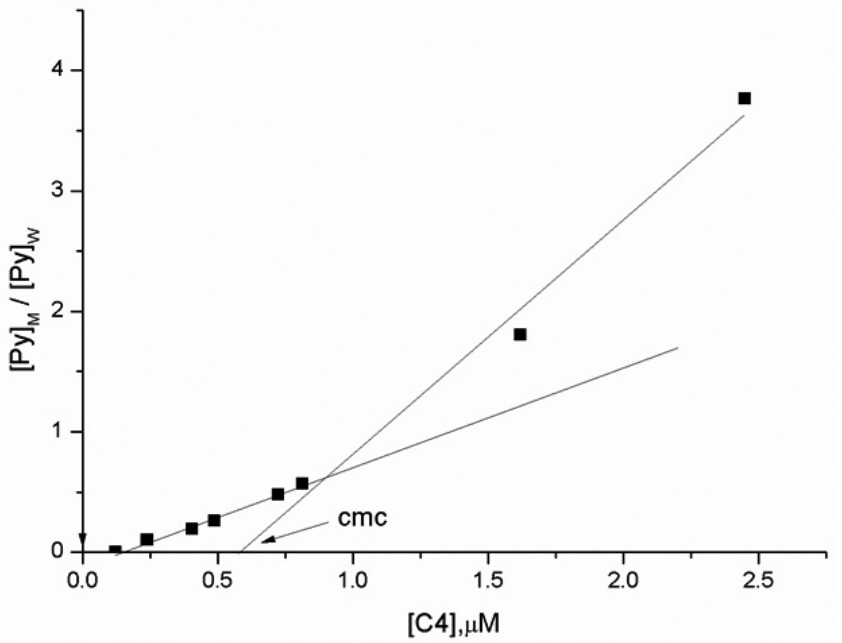

Figure 7. Plot of the ratio $[\mathrm{Py}]_{\mathrm{M}} /[\mathrm{Py}]_{\mathrm{W}}$ against $\mathrm{C} 4$ concentration, according to Wilhelm`s equation (Ref. 37).

Table 4. Critical micelle concentration $\mathrm{CMC}$ and ratio $\mathrm{I}_{1} / \mathrm{I}_{3}$ of block copolymers.

\begin{tabular}{|c|c|c|c|c|}
\hline $\begin{array}{c}\text { Block } \\
\text { copolymer }\end{array}$ & $\begin{array}{c}\text { PMMA- } \\
\text { Cl }\end{array}$ & Composition & $\begin{array}{c}\text { CMC } \\
\text { (M) }\end{array}$ & $\mathbf{I}_{\mathbf{1}} / \mathbf{I}_{\mathbf{3}}$ \\
\hline $\mathrm{C} 1$ & $\mathrm{H} 1$ & $\begin{array}{c}\text { PMMA }_{67}-\mathrm{b}- \\
\text { PHEMA }_{154}\end{array}$ & $9.0 \times 10^{-7}$ & 1.33 \\
\hline $\mathrm{C} 2$ & $\mathrm{H} 2$ & $\begin{array}{c}\mathrm{PMMA}_{20}-\mathrm{b}- \\
\text { PHEMA }_{153}\end{array}$ & $8.2 \times 10^{-7}$ & 1.42 \\
\hline $\mathrm{C} 3$ & $\mathrm{H} 2$ & $\begin{array}{c}\mathrm{PMMA}_{20}-\mathrm{b}- \\
\text { PHEMA }_{135}\end{array}$ & $6.9 \times 10^{-7}$ & 1.45 \\
\hline $\mathrm{C} 4$ & $\mathrm{H} 3$ & $\begin{array}{c}\mathrm{PMMA}_{27}-\mathrm{b}- \\
\text { PHEMA }_{10}\end{array}$ & $1.0 \times 10^{-7}$ & 1.37 \\
\hline $\mathrm{C} 5$ & $\mathrm{H} 3$ & $\begin{array}{c}\mathrm{PMMA}_{27}-\mathrm{b}- \\
\text { PHEMA }_{88}\end{array}$ & $5.8 \times 10^{-7}$ & 1.46 \\
\hline
\end{tabular}

The ratio $I_{1} / I_{3}$ of the intensities of the bands that appear at $380 \mathrm{~nm}\left(I_{1}\right)$ and $390 \mathrm{~nm}\left(\mathrm{I}_{3}\right)$ has been proposed as an empirical polarity scale ${ }^{36,39}$. At high polymer concentration (above CMC) the value of the ratio $\mathrm{I}_{1} / \mathrm{I}_{3}$ represents the polarity sensed by pyrene in the hydrophobic sites provided by the polymer micelle. Therefore, a comparison of these values provides a relative measure of the micelle micropolarity. The data in table 4 show that the values of the ratio $\mathrm{I}_{1} / \mathrm{I}_{3}$ vary slightly with the copolymer composition, i.e. $1.33-1.46$. This result suggests that increasing the number of MMA units from 67 to 275 , or the number of HEMA units from 10 to 154 , has not effect on the core hydrophobicity. On the other hand, the micropolarity sensed by pyrene in these micelles is higher than that determined in aggregates formed by block copolymers where PS is the hydrophobic block ${ }^{5,6,38}$.

\section{CONCLUSIONS}

In this study amphiphilic block copolymers of PMMA and PHEMA with different block lengths have been synthesized by two successive ATRP polymerizations. The results indicate that a good control of copolymerization is achieved by using chloride terminated PMMA as macroinitiator. The amphiphilic character of the block copolymer was modulated by varying the molecular weight of PMMA-Cl, and/or by varying the degree of polymerization of HEMA in the second block. Thermal degradation studies of both PMMA and block copolymers PMMA-b-PHEMA indicate that degradation occurs in one stage and is due to random chain scission. In addition, single glass transition temperatures were detected for all polymers indicating that in the glassy state the polymer chains are statistically distributed.

The self-assembly of PMMA-b-PHEMA in aqueous solution was investigated by fluorescence probing. Interestingly, the critical micelle concentration depends both on the relative sizes of hydrophobic and hydrophilic blocks. This result suggests that the free energy of micellization receives contributions from the hydrophobic effect and from the interaction between water and the polar block. 


\section{ACKNOWLEDGMENTS}

This work has been funded by UNAB DI-309-13/R and FONDECYT No 1130742. B. Acevedo thanks UNAB for Ph.D. fellowship.

\section{REFERENCES}

1. M. L. Adams, A. Lavasanifar, and G. S. Kwon J. Pharm. Sci., 92, 1343 (2003)

2. K. Kataoka, A. Harada, and Y. Nagasaki Adv. Drug Deliv. Rev., 47, 113 (2001)

3. A. V. Kabanov and V. Y. Alakhov, in Amphiphilic Block Copolymers. Self-assembly and applications, P. Alexandridis and B. Lindman, Ed., Elsevier. Amsterdam, 2000.

4. C. Allen, D. Maysinger, and A. Eisenberg Colloids Surf. , B, 16, 3 (1999)

5. B. Urbano, P. Silva, A. F. Olea, I. Fuentes, and F. Martinez J. Chil. Chem. Soc., 53, 1507 (2008)

6. A. F. Olea, P. Silva, I. Fuentes, F. Martinez, and D. Worrall J. Photochem. Photobiol. A: Chem., 217, 49 (2011)

7. Z. S. Gao and A. Eisenberg Macromolecules, 26, 7353 (1993)

8. G. H. Zhang, K. Khougaz, M. Moffitt, and A. Eisenberg, in Amphiphilic Block Copolymers. Self-assembly and applications, P. Alexandridis and B. Lindman, Ed., Elsevier. Amsterdam, 2000.

9. P. Alexandridis and Lindman B., Amphiphilic Block Copolymers, SelfAssembly and Applications, Elsevier Science, Amsterdam, 2000

10. R. L. Xu, M. A. Winnik, G. Riess, B. Chu, and M. D. Croucher Macromolecules, 25, 644 (1992)

11. K. Yu and A. Eisenberg Macromolecules, 31, 3509 (1998)

12. P. Alexandridis and T. A. Hatton Colloids Surf., A, 96, 1 (1995)

13. I. Volfova, B. Rihova, V. Vetvicka, P. Rossman, and K. Ulbrich J. Bioact. Compat. Pol., 7, 175 (1992)

14. M. Fischer, C. P. Baptista, I. C. Goncalves, B. D. Ratner, C. Sperling, C. Werner, C. L. Martins, and M. A. Barbosa Biomaterials, 33, 7677 (2012)

15. B. D. Ratner and A. S. Hoffman, in Hydrogels for Medical and Related Applications, J. D. Andrade, Ed., ACS Symposium Series, American Chemical Society. Washington, 1976.

16. F. Chiellini, F. Petrucci, E. Ranucci, and R. Solaro J. Appl. Polym. Sci., $85,2729(2002)$

17. P. C. Nicolson and J. Vogt Biomaterials, 22, 3273 (2001)

18. S. Atzet, S. Curtin, P. Trinh, S. Bryant, and B. Ratner Biomacromolecules,
9, $3370(2008)$

19. L. Yuan, W. L. Chen, J. Li, J. H. Hu, J. J. Yan, and D. Yang J. Polym. Sci. Part A-Polym. Chem., 50, 4579 (2012)

20. F. J. Xu, H. Z. Li, J. Li, Z. X. Zhang, E. T. Kang, and K. G. Neoh Biomaterials, 29, 3023 (2008)

21. K. Ishizu, S. Takano, T. Murakami, S. Uchida, and M. Ozawa J. Appl. Polym. Sci., 109, 3554 (2008)

22. M. Kato, M. Kamigaito, M. Sawamoto, and T. Higashimura Macromolecules, 28, 1721 (1995)

23. J. Wang and K. Matyjaszewski J. Am. Chem. Soc., 117, 5614 (1995)

24. K. Matyjaszewski and J. Xia Chem. Rev., 101, 2921 (2001)

25. K. L. Beers, S. Boo, S. G. Gaynor, and K. Matyjaszewski Macromolecules, 32, 5772 (1999)

26. K. L. Robinson, M. A. Khan, M. V. D. Banez, X. S. Wang, and S. P. Armes Macromolecules, 34, 3155 (2001)

27. T. L. Wang, Y. Z. Liu, B. C. Jeng, and Y. C. Cai J. Polym. Res., 12, 67 (2005)

28. J. V. M. Weaver, I. Bannister, K. L. Robinson, X. Bories-Azeau, S. P. Armes, M. Smallridge, and P. McKenna Macromolecules, 37, 2395 (2004)

29. G. D. Pizarro, O. G. Marambio, M. Jeria-Orell, M. E. Flores, and B. L. Rivas J. Appl. Polym. Sci., 118, 3649 (2010)

30. R. P. Johnson, Y. I. Jeong, E. Choi, C. W. Chung, D. H. Kang, S. O. Oh, H. Suh, and I. Kim Adv. Funct. Mater., 22, 1058 (2012)

31. M. Yin, W. A. Habicher, and B. Voit Polymer, 46, 3215 (2005)

32. K. L. Beers, S. G. Gaynor, K. Matyjaszewski, S. S. Sheiko, and M. Moller Macromolecules, 31, 9413 (1998)

33. H. Mori, O. Wakisaka, A. Hirao, and S. Nakahama Macromol. Chem. Physics, 195, 3213 (1994)

34. J. L. de la Fuente, M. Wilhelm, H. W. Spiess, E. L. Madruga, M. Fernandez-Garcia, and M. L. Cerrada Polymer, 46, 4544 (2005)

35. T. Caykara, C. Ozyurek, and O. Kantoglu J. Appl. Polym. Sci., 103, 1602 (2007)

36. K. Kalyanasundaram and J. K. Thomas J. Am. Chem. Soc., 99, 2039 (1977)

37. I. V. Astafieva, X. F. Zhong, and A. Eisenberg Macromolecules, 26, 7339 (1993)

38. M. Wilhelm, C. L. Zhao, Y. C. Wang, R. L. Xu, M. A. Winnik, J. L. Mura, G. Riess, and M. D. Croucher Macromolecules, 24, 1033 (1991)

39. D. C. Dong and M. A. Winnik Photochem. Photobiol., 35, 17 (1982) 